\title{
TRAINEE SECTION
}

Jodie I. Roberts

Jennifer K. Beatty

Michael A. Peplowski

Michael B. Keough

Bryan G. Yipp

Morley D. Hollenberg

Paul L. Beck

\section{Highlights from the 6th Annual University of Calgary Leaders in Medicine Research Symposium and the Keynote Address by Dr. Danuta Skowronski}

Highlights from the 6th Annual University of Calgary Leaders in Medicine Research Symposium and the Keynote Address by Dr. Danuta Skowronski

Clin Invest Med 2015; 38 (6): E314-E317. 
The Leaders in Medicine (LIM) Program at the University of Calgary hosted its $6^{\text {th }}$ Annual Research Symposium on November 14, 2014, showcasing the quality and breadth of work performed by students at the Cumming School of Medicine. Participation at this year's event was our most successful to date, with a total of six oral and 77 poster presentations during the afternoon symposium. For a detailed description of the work presented at the symposium, please see the Proceedings from the $6^{\text {th }}$ Annual University of Calgary Leaders in Medicine Research Symposium published in this issue of Clinical and Investigative Medicine.

We were particularly honoured to host Dr. Danuta Skowronski as the keynote speaker for this year's Leaders in Medicine Research Symposium. Dr. Skowronski completed her medical degree and family medicine training at Queen's University in Kingston, Ontario. She then completed a Master's of Health Science degree in Health Care and Epidemiology and a Fellowship in Community Medicine at the University of British Columbia. In the years following, she worked as an Associate Medical Health Officer in Surrey, British Columbia before being certified with the American Board of Preventive Medicine and completing a diploma in Infectious Disease Epidemiology with the London School of Hygiene and Tropical Medicine in London, UK. In 1998, Dr. Skowronski joined the British Columbia Centre for Disease Control (BCCDC) where she assumed responsibility for surveillance, research and program and policy recommendations related to respiratory

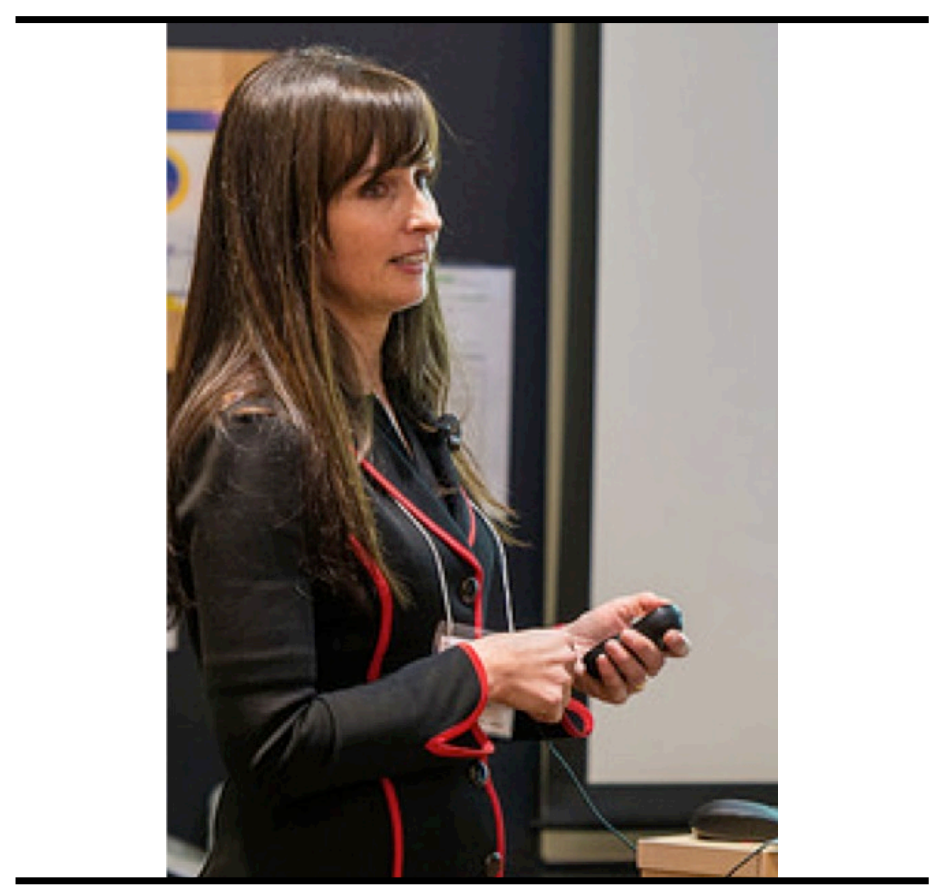

Dr. Danuta Skowronski pathogens and vaccine-preventable diseases. Over the ensuing years, Dr. Skowronski's primary focus at the BCCDC became influenza and emerging or re-emerging respiratory pathogens.

Dr. Skowronski has served as the Epidemiology Lead for Influenza and Emerging Respiratory Pathogens at the BCCDC for the past 15 years. Her leadership in the fields of rapid response research and real time risk assessment is invaluable. She is widely recognized for her role in risk assessment, response and communication concerning emerging public health issues to the public. Dr. Skowronski has more than 100 publications, primarily related to influenza, emerging respiratory pathogens and vaccine-preventable diseases. She has been the recipient of numerous awards, including the James M. Robinson Award for significant contributions to public health and the UBC President's Award for public education through media. Dr. Skowronski was also named among the 100 most influential women in BC by the Vancouver Sun.

Dr. Skowronski was chosen as this year's keynote speaker on the basis of her extensive work and expertise in epidemiology and rapid response research, coupled with her leadership in establishing partnerships between basic scientists and epidemiologists across Canada. These partnerships have resulted in a national surveillance-research platform that provides real-time linking of genotypic, phenotypic and epidemiologic indicators of vaccine-virus relatedness and vaccine protection. In particular, Dr. Skowronski's pioneering development of the testnegative study design for annual influenza vaccine effectiveness monitoring has since been emulated by the Centers for Disease Control and Prevention in the United States, Europe and around the globe. Findings based on that methodologic innovation now contribute to twice yearly meetings of the vaccine strain selection committee of the World Health Organization, which updates components of the annually-revised world-wide influenza vaccine.

Attendees of the Annual LIM Research Symposium were fortunate to glean an inside view of the excitement and complexities of rapid response to public health crises from Dr. Skowronski. During her very engaging presentation entitled "Rapid response research during emerging public health crises: influenza and reflections from the five year anniversary of the 2009 pandemic", Dr. Skowronski highlighted some examples of applied public health and rapid response research with compressed timelines for decision-making that she has faced during her leadership at the BCCDC. These scenarios included the BCCDC response to the $2009 \mathrm{H} 1 \mathrm{~N} 1$ pandemic, the SARS outbreak of 2003 and oculo-respiratory syndrome; an unexpected adverse event that arose during the roll-out of the 20002001 Canadian influenza vaccination campaign. 
Dr. Skowronski presented the well-coordinated response of the BCCDC to SARS in 2003 to demonstrate the importance of having a centralized system for early detection and management of communicable diseases (see: Skowronski DM et al. Emerg Infect Dis 2006 Jan;12(1):155-8; available at: http://wwwnc.cdc.gov/eid/article/12/1/05-0327 article). In 2003, the BCCDC was well-rehearsed to manage a potential pandemic and, as a result, the SARS outbreak in the Vancouver census metropolitan area (VCMA) was well-contained. In the two-week period leading up to the first case of SARS in the VCMA, an existing electronic distribution system sent four separate alerts to healthcare facilities across the province urging health care providers to be on alert for severe influenza-like illness in travelers returning from mainland China or Hong Kong owing to reports of severe respiratory illness in that region. A number of these BCCDC alerts preceded advisories from the World Health Organization; therefore, when SARS patient zero presented to a Vancouver emergency room, respiratory precautions were instituted within 15 minutes and the patient was transferred to a negative-pressure isolation room (NPIR) within 2.5 hours. Two additional imported cases were admitted directly to an NPIR upon presenting to hospital and one additional case recovered at home and did not present to hospital. From these four index cases, the disease was transmitted to only one additional person - a nurse caring for one of the SARS patients. Despite droplet and contact protection, a flushed toilet resulted in aerosolized particles, infecting the nurse due to the absence of adequate eye protection (which was not recommended at that time). Fortunately, all five SARS cases in the VCMA recovered fully. In grave contrast, Ontario did not have a centralized system responsible for communicable disease control at this time. Ultimately, the greater Toronto area (GTA) reported 247 cases (three imported) and 43 deaths. Health care workers at the facility receiving the index patient in Toronto were unaware of the emerging issues in Hong Kong or that the index patient had travel links to that area through the infected mother who had recently returned from Hong Kong and had died at home from severe respiratory illness, infecting several members of the family who then presented for care. Consequently, the initial index case for the GTA was not recognized as a special threat, and was not placed in airborne isolation until already in hospital for 21 hours. This delay led to substantial onward transmission in the GTA, which the VCMA had avoided through early recognition and infection control response, triggered in part by timely communications. This SARS example has relevance to other emerging respiratory viruses, including coronaviruses such as Middle East Respiratory Syndrome coronavirus (MERS-CoV), with the poten- tial for importation of travel-related cases and nosocomial amplification.

Dr. Skowronski discussed her experiences in developing vaccine safety recommendations with reference to oculorespiratory syndrome (ORS). ORS was a previously unrecognized adverse event associated with the influenza vaccine and was identified in 960 Canadians during the 2000-2001 influenza vaccine campaign. Early on in the campaign, Dr. Skowronski received multiple reports of bilateral red eyes and respiratory symptoms that onset within a few hours following influenza vaccination. National discussion confirmed that cases of ORS were occurring in a number of Canadian provinces. Nearly all cases $(96 \%)$ were linked to one Canadian manufacturer's vaccine, and it was determined that the vaccines from this manufacturer contained an excess of aggregated unsplit influenza virions. Given these findings, and knowing that tens of thousands of individuals were being immunized each day, difficult and time-sensitive decisions had to be made about whether to halt or continue the influenza immunization campaign. This required urgent epidemiologic, immunologic and animal studies to gauge the frequency and severity of this adverse event, the results of which were then balanced against the risks associated with influenza itself. In response, Dr. Skowronski led numerous studies in collaboration with a multidisciplinary team of laboratory scientists and epidemiologists nationally to identify the cause of the syndrome and to inform policy makers. The following year, additional studies were undertaken, including a randomized control trial with a network of vaccine researchers, to estimate the risk of recurrence when re-vaccinating individuals who had been affected by ORS in 2000.

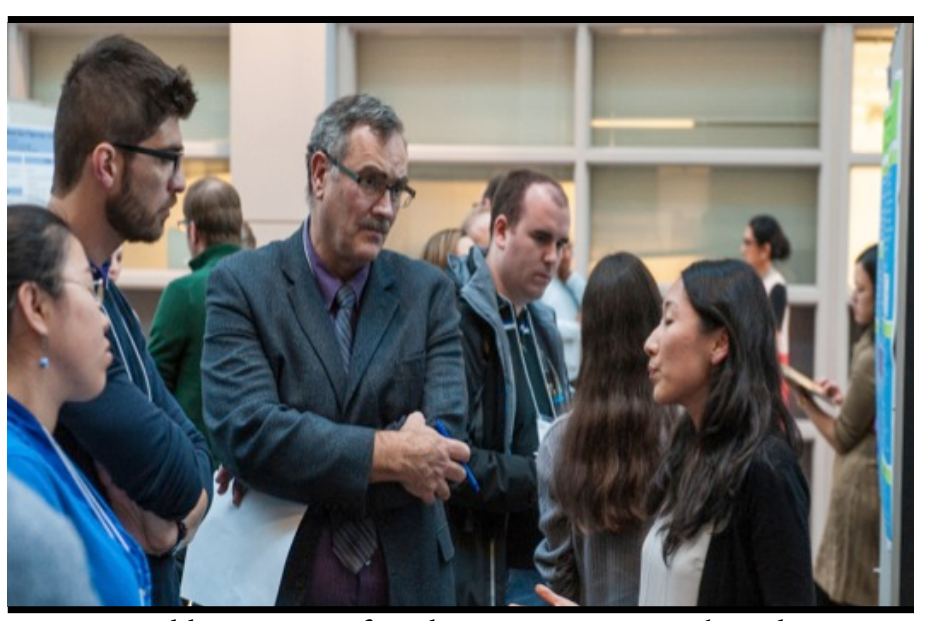

Dr. Jon Meddings, Dean of Medicine, interacting with students during the poster presentations. 
In addition to her keynote address at the symposium, Dr. Skowronski was kind enough to provide students with a lighthearted discussion of her career path and relevant examples related to her epidemiology and rapid response research. In addition to interacting with and inspiring students in the LIM Program, Dr. Skowronski also presented some of her work to undergraduate students in the Bachelor of Health Sciences Program in the Cumming School of Medicine.
The Research Symposium was an outstanding success, with over 100 students attending and over 30 staff participating. Dr. Jonathan Meddings, Dean of Medicine, presented the opening remarks and attended the entire event, where he acted as a judge for both oral and poster presentations. Several awards were given out for top oral and poster presentations.

LIM is a program for students interested in combining research, business and other academics interests with their medical education and is run almost entirely by the student body.

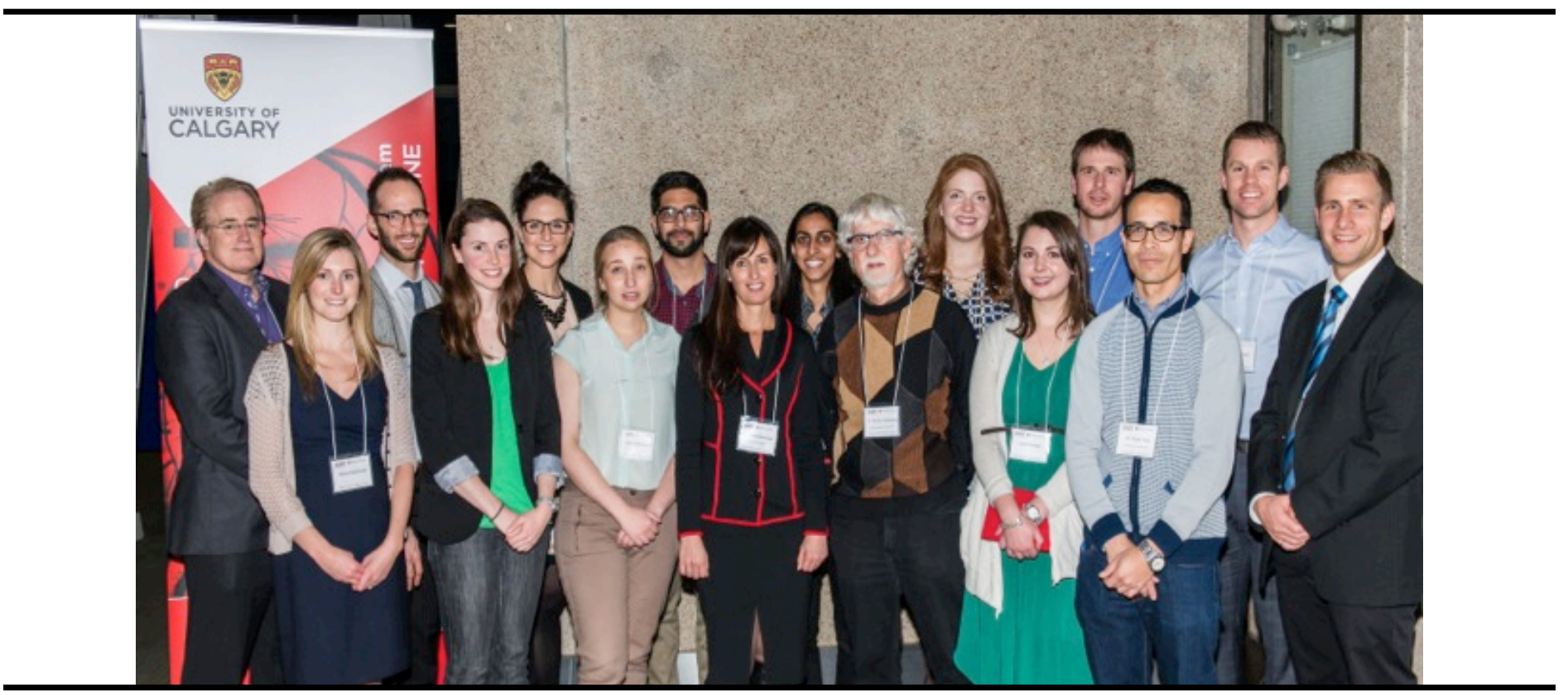

LIM Staff; Dr. P. Beck, Dr. M. Hollenberg and Dr. B. Yipp, with special guest Dr. D. Skowronski and the Awards Winners. 